\title{
Article \\ Direct and Competitive Optical Grating Immunosensors for Determination of Fusarium Mycotoxin Zearalenone
}

\author{
Inna Székács ${ }^{1}$, Nóra Adányi ${ }^{2}$, István Szendrő ${ }^{3}$ and András Székács ${ }^{4, *}$ (D) \\ 1 Nanobiosensorics Group, Institute for Technical Physics and Material Science, Centre for Energy Research, \\ Konkoly-Thege M. út 29-33, H-1121 Budapest, Hungary; szekacs@mfa.kfki.hu \\ 2 Food Science Research Institute, National Agricultural Research and Innovation Centre, Herman O. út 15, \\ H-1022 Budapest, Hungary; adanyi.nora@eki.naik.hu \\ 3 MicroVacuum Ltd., Kerékgyártó u. 10, H-1147 Budapest, Hungary; istvan.szendro@microvacuum.com \\ 4 Agro-Environmental Research Institute, National Research and Innovation Centre, Herman Ottó út 15, \\ H-1022 Budapest, Hungary \\ * Correspondence: szekacs.andras@akk.naik.hu; Tel.: +36-30-927-2297
}

Citation: Székács, I.; Adányi, N.; Szendrő, I.; Székács, A. Direct and Competitive Optical Grating Immunosensors for Determination of Fusarium Mycotoxin Zearalenone.

Toxins 2021, 13, 43.

https://doi.org/10.3390/toxins13010043

Received: 1 December 2020

Accepted: 5 January 2021

Published: 8 January 2021

Publisher's Note: MDPI stays neutral with regard to jurisdictional clai$\mathrm{ms}$ in published maps and institutional affiliations.

Copyright: (C) 2021 by the authors. Licensee MDPI, Basel, Switzerland. This article is an open access article distributed under the terms and conditions of the Creative Commons Attribution (CC BY) license (https:// creativecommons.org/licenses/by/ $4.0 /)$.

\begin{abstract}
Novel optical waveguide lightmode spectroscopy (OWLS)-based immunosensor formats were developed for label-free detection of Fusarium mycotoxin zearalenone (ZON). To achieve low limits of detection (LODs), both immobilised antibody-based (direct) and immobilised antigen-based (competitive) assay setups were applied. Immunoreagents were immobilised on epoxy-, amino-, and carboxyl-functionalised sensor surfaces, and by optimising the immobilisation methods, standard sigmoid curves were obtained in both sensor formats. An outstanding LOD of $0.002 \mathrm{pg} / \mathrm{mL}$ was obtained for $\mathrm{ZON}$ in the competitive immunosensor setup with a dynamic detection range between 0.01 and $1 \mathrm{pg} / \mathrm{mL}$ ZON concentrations, depending on the covalent immobilisation method applied. This corresponds to a five orders of magnitude improvement in detectability of ZON relative to the previously developed enzyme-linked immonosorbent assay (ELISA) method. The selectivity of the immunosensor for ZON was demonstrated with structural analogues ( $\alpha$-zearalenol, $\alpha$-zearalanol, and $\beta$-zearalanol) and structurally unrelated mycotoxins. The method was found to be applicable in maize extract using acetonitrile as the organic solvent, upon a dilution rate of 1:10,000 in buffer. Thus, the OWLS immunosensor method developed appears to be suitable for the quantitative determination of $\mathrm{ZON}$ in aqueous medium. The new technique can widen the range of sensoric detection methods of ZON for surveys in food and environmental safety assessment.
\end{abstract}

Keywords: mycotoxin; zearalenone; immunosensor; optical waveguide lightmode spectroscopy; label-free detection

Key Contribution: A real time, label-free OWLS immunosensor with a dynamic detection range between 0.01 and $1 \mathrm{pg} / \mathrm{mL}$ and an outstanding limit of detection of $0.002 \mathrm{pg} / \mathrm{mL}$ was developed and validated in maize extract for zearalenone. The novel immunosensor showed a five orders of magnitude improvement in analytical sensitivity for zearalenone compared to ELISA.

\section{Introduction}

Zearalenone $(\mathrm{ZON})$ is a mycotoxin produced by several Fusarium species, most frequently by F. graminearum, and is commonly found in maize and also in wheat, barley, sorghum, and rye throughout various countries of the world, causing substantial human exposure [1]. ZON and its metabolites have oestrogenic activity in several species [2-5] accompanied by hepatotoxicity, haematotoxicity, immunotoxicity, and genotoxicity [6-8]. No uniform regulations have been imposed for this toxin in different countries. Tolerance levels in grains and grain products have been set in several countries at a concentration range of 20 to $1000 \mu \mathrm{g} / \mathrm{kg}$ [9], e.g., 20 to $200 \mu \mathrm{g} / \mathrm{kg}$ in unprocessed and processed cereal products in the EU [10]. Data evaluation on the most sensitive animal species-swine-and 
comparing with humans, a tolerable daily intake for ZON has been set as $0.25 \mu \mathrm{g} / \mathrm{kg}$ body weight $[11,12]$.

Common analytical methods for identifying and quantifying mycotoxins include thin-layer chromatography (TLC) [13,14] or high-pressure TLC [15], laser fluorimetry [16], gas chromatography (GC) [14] often coupled with mass spectrometry (GC-MS) [17,18], high-performance liquid chromatography (HPLC) [19-21] with standardised sample preparation [22,23], ultra-performance liquid chromatography (UPLC) [24], and capillary electrophoresis $[25,26]$. HPLC methods have become the most widespread for mycotoxin analysis. These methods are sensitive and accurate but require extensive sample preparation steps, well-trained personnel, and expensive instrumentation. Therefore, just as for other mycotoxins, and on the basis of the historical radioimmunoassay method [27], immunochemical methods, e.g., enzyme-linked immunosorbent assays (ELISAs), have been developed and utilised for rapid screening of ZON [14,19,28-33]. These immunoassays were further amplified with fluorescent quantum dots [34-36], magnetic nanoparticles [37], or helical carbon nanotubes [38]. Alternatively, antibodies [24,36,39-44] or molecularly imprinted polymers [45-47] could be applied for affinity chromatography or pre-column sample purification prior to chromatographic analyses (HPLC, UPLC). Similarly, nanoparticleassisted lateral flow immunochromatographic strips [48,49] were devised, occasionally with surface-enhanced Raman scattering detection [50]. Recently, micro- and nanoarray immunoassays were reported in microplate-based [51] or microfluidic sensor-based [52] setups. A cut-off level of $100 \mu \mathrm{g} / \mathrm{kg}$ was established (4 min) for ZON and T2 toxin in a gel-based immunoassay [53]. Fluorescence polarisation immunoassays allowed for a detection range for ZON of 150-1000 $\mu \mathrm{g} / \mathrm{kg}$ and a limit of detection (LOD) of $137 \mu \mathrm{g} / \mathrm{kg}$, and required less than 2 min per sample to carry out [54]. A magnetic nanotag-based immunoassay [55] and a multiplexed quantum dot immunochromatographic assay [56] allowed the parallel detection of $\mathrm{ZON}$ in the presence of other mycotoxins. Label-free biosensors on the basis of antibodies [57-60], aptamers [58,61-67], or molecularly imprinted polymers [68-71] as recognition elements have also been developed with various signal amplification and detection routes involved, and the range of sensoric detection techniques is expanding [72]. Thus, a surface plasmon resonance (SPR) biosensor has been developed for the simultaneous detection of four mycotoxins, with an LOD below $0.2 \mathrm{ng} / \mathrm{mL}$ for ZON [73], a gold nanoparticle-amplified imaging SPR (iSPR) biosensor allowed an LOD for ZON of $59.2 \mathrm{pg} / \mathrm{mL}$ in multiplex mycotoxin determination [74], a method of total internal reflection ellipsometry (TIRE) allowed detection of $\mathrm{ZON}$ at concentrations as low as $0.1 \mathrm{ng} / \mathrm{mL}$ [75], and electrochemical sensors resulted in LODs of $0.15-0.25 \mathrm{pg} / \mathrm{mL}[42,60]$. The immunosensors developed allow rapid quantitative determination of the target compounds in plant samples and in environmental matrices, mainly in ground water.

Immunosensors based on the technique of optical waveguide lightmode spectroscopy (OWLS) have been applied with success to detect different molecules, and gained importance in environmental and food analysis [59,76,77]. In the current study, an OWLS immunosensor has been developed for the determination of ZON in maize samples. Different chemical methods for functionalisation and accordingly for immobilisation were compared regarding analytical sensitivity and sensor stability. Upon optimisation, the novel immunosensor was used for the detection of $\mathrm{ZON}$ contamination in maize and the results were compared to ELISA measurements to demonstrate the outstanding applicability of the method in complex food matrices and assumedly, in environmental samples as well.

\section{Results and Discussion}

OWLS immunosensors were devised both in the direct (immobilised antibody) and competitive (immobilised antigen conjugate)-based formats. Immobilisation of the protein reactants has been carried out by several chemical routes utilising hydroxyl groups on the sensor surface converted into epoxy or amino functionalities, further reacted with appropriate chemical reagents for covalent immobilisation of the protein immunoreagents (Figure 1). 


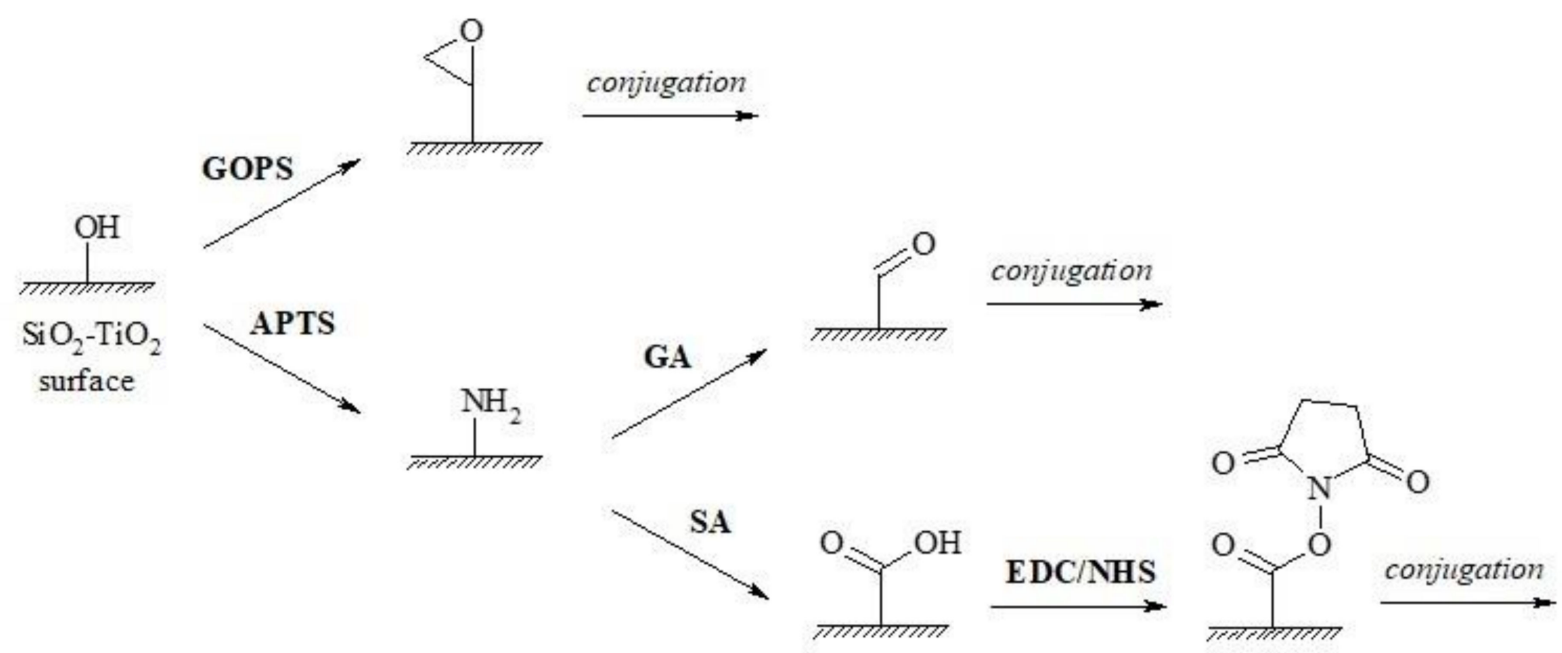

Figure 1. Functionalisation of the sensor surface with epoxy, amino, or carboxyl functional groups. GOPS: $\gamma$-glycidoxypropyltrimethoxysilane; APTS: (3-aminopropyl) triethoxysilane; GA: glutaraldehyde; SA: succinic anhydride; EDC: 1-ethyl-3-(3dimethylaminopropyl) carbodiimide; NHS: N-hydroxysuccinimide.

\subsection{Direct Immunosensor}

Immunoglobulin ( $\mathrm{IgG}$ ) fractions purified from $\mathrm{ZON}$-specific rabbit antisera obtained against a conjugate of $\mathrm{ZON}$ to conalbumin (ovotransferrin, CONA) as an immunogen were used in an immobilised antibody-based (direct) immunosensor format. The main characteristics that determined achievable assay signals were the quality and concentration (dilution) of the ZON-specific antibodies. Using a dilution of the IgG purified from the serum of 1:2000 for immobilisation by all three methods, the epoxy-functionalised sensor surface modified with $\gamma$-glycidoxypropyl-trimethoxysilane (GOPS), as well as the amino-functionalised sensor surface modified with (3-aminopropyl)triethoxysilane (APTS), and glutaraldehyde (GA) or succinic anhydride with 1-ethyl-3-(3-dimethylaminopropyl)carbodiimide and Nhydroxysuccinimide (SA/EDC-NHS), standard calibration curves were obtained for ZON determination by applying ZON onto the immobilised antibodies on the sensor surface at various concentrations up to $100 \mu \mathrm{g} / \mathrm{mL}$ (Figure 2).

The highest sensor signals were obtained by APTS/GA modification, followed by APTS/SA-EDC/NHS, while immobilisation with GOPS provided the lowest assay signals. Detection sensitivity, characterised with the analyte (ZON) $50 \%$ effective concentrations $\left(\mathrm{EC}_{50}\right)$ corresponding to the half-maximal signal level, indicated $\mathrm{EC}_{50}$ values of $3.6 \pm 0.2$, $2.2 \pm 0.6$, and $1.1 \pm 0.1 \mu \mathrm{g} / \mathrm{mL}$ for the GOPS, APTS/GA, and APTS/SA-EDC/NHS modifications, respectively. Signal intensities and statistics indicated that immobilisation on the epoxy-modified surface (GOPS) provided lower binding efficacy and reproducibility than that on amino-modified surfaces (APTS) with homo-bifunctional cross-linking (GA) with further modification to carboxyl groups (SA/EDC-NHS). Nonetheless, the lowest detectable ZON concentrations in these setups were in all three cases above $500 \mathrm{ng} / \mathrm{mL}$, which is not sufficiently sensitive for analysis of real samples. 


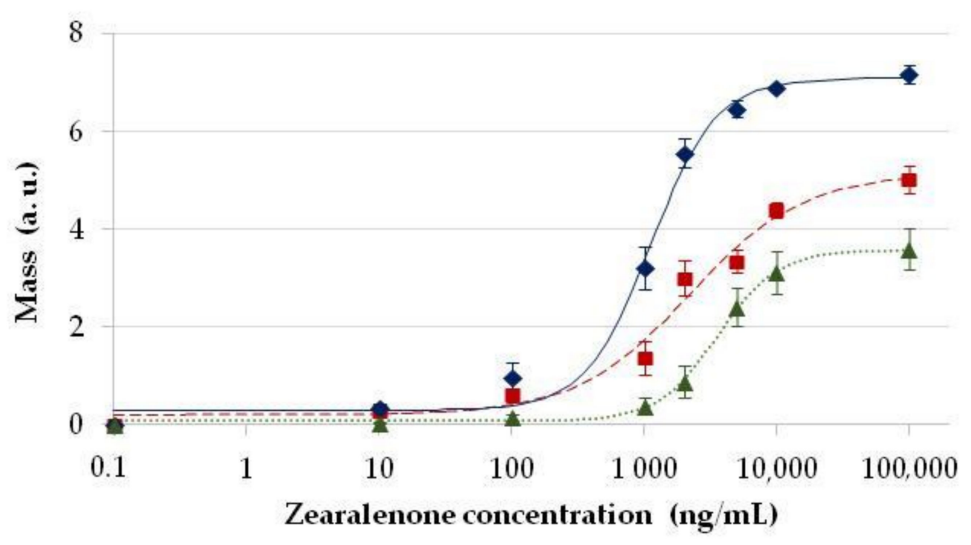

Figure 2. Standard calibration curves for zearalenone $(\mathrm{ZON})$ determination by the direct optical waveguide lightmode spectroscopy (OWLS) immunosensor format. Sensor signals proportional to relative surface mass $\left(\mathrm{ng} \mathrm{mm}^{-2}\right)$ on the OWLS sensor, expressed in arbitrary units (a.u.), as a function of concentration of $\mathrm{ZON}$ applied in the calibration standard samples in the sensor format with ZON-specific serum immobilised on amino- and epoxy-modified sensor surfaces using (3-aminopropyl) triethoxysilane and glutaraldehyde (APTS/GA) ( $\boldsymbol{\square}$, red dashed line), (3-aminopropyl) triethoxysilane, succinic anhydride and 1-ethyl-3-(3-dimethylaminopropyl) carbodiimide with N-hydroxysuccinimide (APTS/SA/EDC-NHS) ( $\downarrow$, blue solid line), and $\gamma$ glycidoxypropyl-trimethoxysilane (GOPS) ( $\boldsymbol{\Lambda}$, green dotted line).

\subsection{Competitive Immunosensor}

\subsubsection{Serum Titration}

The polyclonal IgG fraction purified ZON-specific rabbit antisera obtained against ZON-CONA as an immunogen were titrated in the OWLS immunosensor setup using a protein-heterologous conjugate to bovine serum albumin (BSA) at a ZON-BSA concentration of $10 \mu \mathrm{g} / \mathrm{mL}$ as a sensor surface antigen. Purified antisera were injected onto this sensor surface at increasing concentrations (decreasing dilutions) to assess the binding affinity of the antibodies. Typical titration curves are shown in Figure 3, indicating the peak signals obtained in the flow-through system in 3.4 min upon injection, decreasing peak intensities with increasing serum dilution and optimal dilution (the highest dilution still allowing distinguishable signal) at a serum dilution of 1:2000. The use of more concentrated serum for further competitive measurements results in deteriorated method sensitivity, while lower antibody concentrations allow for less stable sensor performance.

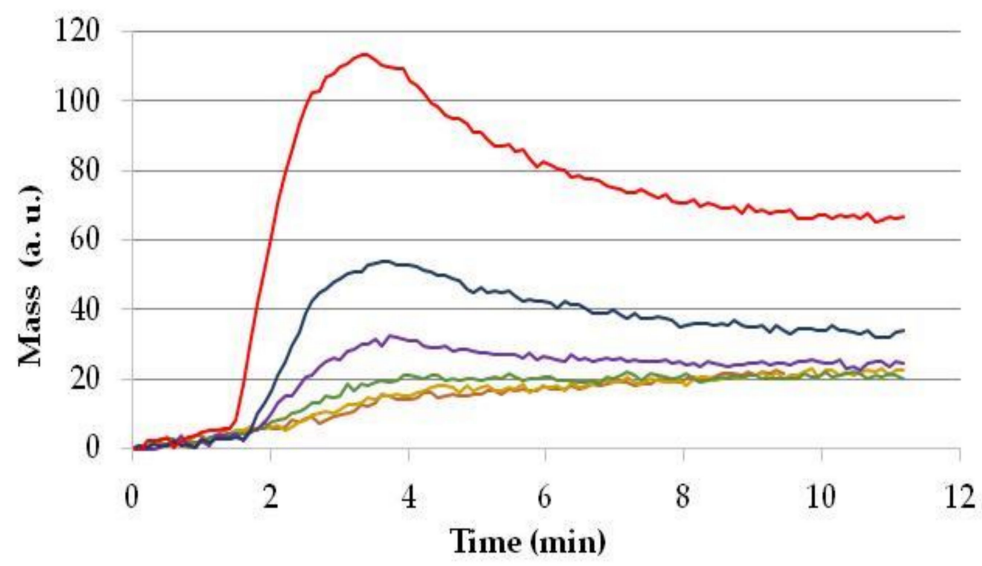

Figure 3. Optimisation of serum dilution by recording sensor responses to polyclonal antiserum at various dilutions using a sensor surface modified with $10 \mu \mathrm{g} / \mathrm{mL}$ of zearalenone conjugate to bovine serum albumin. Serum dilutions at 1:500 (red line), 1:1000 (blue line), 1:2000 (purple line), 1:4000 (green line), 1:8000 (yellow line), and 1:16,000 (brown line). 
The determination of the amount of polyclonal IgG applied is essential in both the direct and indirect (competitive) measurements, particularly in the latter as it is a rather sensitive equilibrium. As seen in Figure 3, when the $\operatorname{IgG}$ is applied at small concentrations (high dilutions, e.g., 1:8000 or 1:16,000), antibodies poorly saturate the sensor surface, and small, unstable sensor responses are obtained. On the contrary, in the case of high IgG concentrations (dilutions of 1:500 or 1:1000), although the signal obtained is well measurable (exceeding 100 or 50 arbitrary units, respectively), the surface becomes saturated, and it loses its sensitivity during the measurement of standards and samples. For the measurements, we chose an IgG concentration that is high enough to provide well-measurable signals (at least 20 arbitrary units). On the other hand, the IgG concentration should not be too high, so that the system remains sensitive enough to detect standards containing low amounts of the antigen. Taking the height and shape of the signals into consideration, in the case of competitive measurement of $\mathrm{ZON}$, the dilution of the antibody solution was chosen to be 1:2000.

\subsubsection{Competitive Immunosensor Setups with Different Surfaces Modifications}

The protein-heterologous conjugate of ZON (ZON-BSA) was used as a sensor surface antigen at various concentrations between 2 and $20 \mu \mathrm{g} / \mathrm{mL}$ with the above three immobilisation methods. Upon serum titration, surface coating conditions were optimised for immunosensor sensitivity i.e., analytical standard curves were obtained using concentration series of $\mathrm{ZON}$ and recording its inhibitory effect on antibody binding to the treated immunosensor surfaces (Figure 4).

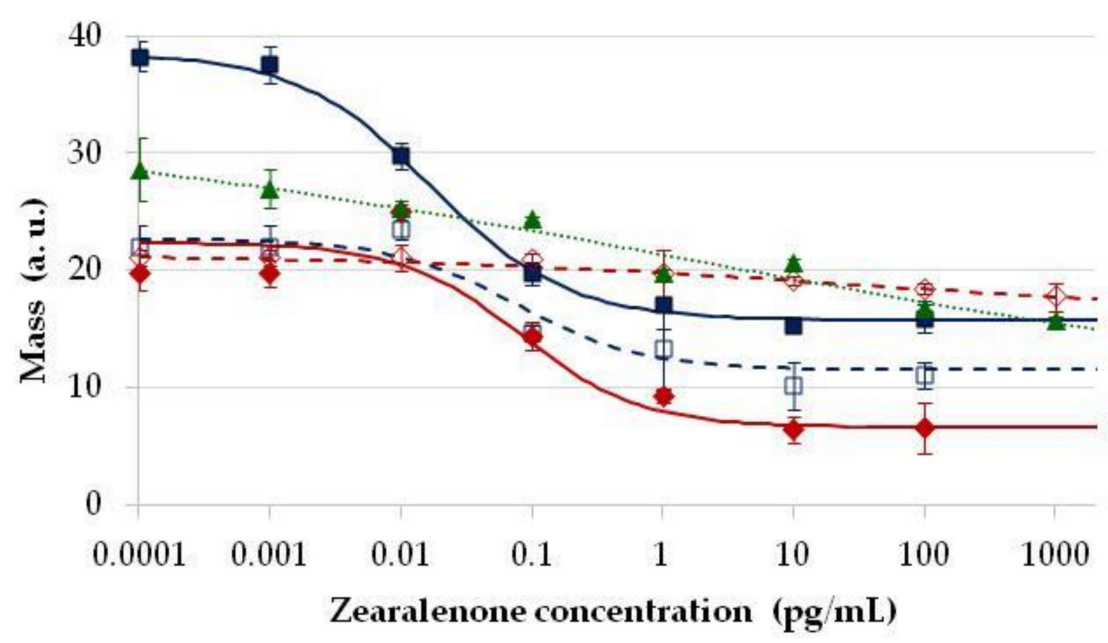

Figure 4. Standard calibration curves for zearalenone (ZON) determination by the competitive optical waveguide lightmode spectroscopy (OWLS) immunosensor format. Sensor signals proportional to relative surface mass ( $\mathrm{ng} \mathrm{mm}^{-2}$ ) on the OWLS sensor, expressed in arbitrary units, as a function of concentration of ZON applied in the calibration standard samples in the sensor format with ZON conjugate to bovine serum albumin (ZON-BSA) immobilised on amino- and epoxy-modified sensor surfaces with (3-aminopropyl) triethoxysilane and glutaraldehyde (APTS/GA) using $10 \mu \mathrm{g} / \mathrm{mL}$ ZON-BSA ( $\square$, blue solid line) and $5 \mu \mathrm{g} / \mathrm{mL}$ ZON-BSA ( $\square$, blue dashed line); (3-aminopropyl) triethoxysilane, succinic anhydride and 1-ethyl-3-(3-dimethylaminopropyl) carbodiimide with $\mathrm{N}$ hydroxysuccinimide (APTS/SA/EDC-NHS) using $10 \mu \mathrm{g} / \mathrm{mL}$ ZON-BSA ( $\downarrow$, red solid line), $5 \mu \mathrm{g} / \mathrm{mL}$ ZON-BSA $(\diamond$, red dashed line), and $\gamma$-glycidoxypropyl-trimethoxysilane (GOPS) ( $\boldsymbol{\Lambda}$, green dotted line).

The highest and stable sensor signals were obtained when ZON-BSA was at $10 \mu \mathrm{g} / \mathrm{mL}$ concentration, above which further improvement in assay signals could not be obtained, and excess of the antigen even caused less reproducible or deteriorated signals. Similarly to the direct sensor format, immobilisation on the epoxy-modified surface (GOPS) was found to be of limited utility in the competitive sensor format as well. Although addition of $\mathrm{ZON}$ resulted in concentration-dependent sensor signals, nonetheless, this means of 
immobilisation was improper for analytical purposes due to the lack of proper regression possibility with the four-parameter logistic fitting. Immobilisation on amino- (APTS/GA) or carboxyl-modified surfaces (APTS/SA/EDC-NHS) allowed for better quantitative detection possibilities, with dynamic detection ranges of $0.001-1 \mathrm{pg} / \mathrm{mL}$ when the antisera were used in 1:2000 dilution. Immobilisation with GA appeared to be applicable at coating levels with ZON-BSA both at 10 and $5 \mu \mathrm{g} / \mathrm{mL}$, while the SA/EDC-NHS method resulted in a standard sigmoid curve only at a coating level of $10 \mu \mathrm{g} / \mathrm{mL}$. In these cases, linear detection ranges were found to be similar with good reproducibility. Antisera obtained from different rabbits (under the same immunisation protocol), although showing somewhat different titration characteristics, provided similar results in the competitive formats, indicating that slight differences in serum composition did not have inhibitory activity. The highest sensor signals were obtained here also by APTS/GA modification. Detection sensitivity showed outstandingly low $\mathrm{EC}_{50}$ values in the range of $0.017-0.083 \mathrm{pg} / \mathrm{mL}$, corresponding to at least six orders of magnitude improvement in detection range compared to the direct immunosensor. The dynamic detection range of $Z O N$ was found in the $0.010-1 \mathrm{pg} / \mathrm{mL}$ ZON concentrations, and an LOD for ZON of $0.002 \mathrm{pg} / \mathrm{mL}$ was obtained in the APTS/GA modification using the ZON-BSA conjugate as the surface coating antigen at $10 \mu \mathrm{g} / \mathrm{mL}$. As the competitive immunosensors based on amino- and carboxyl-modified surfaces provided similar ranges of detection, due to the better reproducibility and longer shelf-life of the latter, the sensor setup using $10 \mu \mathrm{g} / \mathrm{mL}$ of ZON-BSA as the surface coating antigen immobilised with the APTS/SA/EDC-NHS method, as well as ZON-specific antibodies at 1:2000 dilution, was chosen to be used for practical purposes.

\subsection{Immunosensor Specificity}

Immunosensor specificity was tested on the optimised immunosensor setup (see above) by measuring $\mathrm{EC}_{50}$ values obtained with $\mathrm{ZON}$ derivatives and structurally unrelated mycotoxins, and cross-reactivities (CRs), defined as a percentage ratio between the $\mathrm{EC}_{50}$ values of $\mathrm{ZON}$ and the given compound, were calculated. Among the structurally unrelated compounds tested, aflatoxin B1 and ochratoxin did not cause a decrease in the OWLS sensor signal up to $1000 \mathrm{ng} / \mathrm{mL}$ concentration in the diluted standards. Among the compounds tested, only $\alpha$-zearalenol, $\alpha$-zearalanol, and $\beta$-zearalanol showed significant CRs (Table 1 ) with $\mathrm{ZON}$ in the competitive immunosensor format. These are major reductive metabolites of $\mathrm{ZON}$ in mammals, but are also formed to a lesser extent in plants as well [12]; therefore, the potential presence of these metabolites should be also considered upon positive detection of $\mathrm{ZON}$ in commodities by the current immunosensor method. These $\mathrm{CR}$ values are in good agreement with the corresponding values reported for our ELISA system for ZON [29]; however, the detection sensitivity of the current OWLS immunosensor exceeds that of the ELISA by five orders of magnitude. Such outstanding improvement in the detection range of an OWLS immunosensor compared to the corresponding ELISA has been reported [59,78].

Table 1. Percentage of cross-reactivity (CR\%) of the competitive OWLS immunosensor and the corresponding ELISA method [29] with zearalenone and its derivatives.

\begin{tabular}{|c|c|c|c|c|}
\hline \multirow{2}{*}{ Compound } & \multicolumn{2}{|c|}{ OWLS Sensor } & \multicolumn{2}{|c|}{ ELISA } \\
\hline & $\mathrm{IC}_{50}(\mathrm{pg} / \mathrm{mL})$ & $\mathrm{CR} \%{ }^{1}$ & $\mathrm{IC}_{50}(\mathrm{ng} / \mathrm{mL})$ & $C \mathrm{R}^{2}{ }^{1}$ \\
\hline zearalenone & 14.3 & 100 & 14.1 & 100 \\
\hline$\alpha$-zearalenol & 56.5 & 25.2 & 50.1 & 28.2 \\
\hline$\alpha$-zearalanol & 111.0 & 12.8 & 199.5 & 7.1 \\
\hline$\beta$-zearalanol & 526.5 & 2.7 & 1259.0 & 1.1 \\
\hline
\end{tabular}

${ }^{1}$ Cross-reactivity defined as the percentage ratio of the $50 \%$ inhibitory concentration $\left(\mathrm{IC}_{50}\right)$ values of zearalenone and of the given derivative. 


\subsection{Method Validation in Commodity Matrix}

The optimised competitive immunosensor was applied to determine ZON concentrations in maize commodity. For this purpose, maize samples spiked with $\mathrm{ZON}$ at concentration levels of $0-10 \mu \mathrm{g} / \mathrm{kg}$ were extracted in acetonitrile/water (6:4), and were analysed by the competitive OWLS immunosensor and ELISA. These analyses aimed to assess matrix effects by the maize extract on the one hand, and were also targeted to investigate whether the two analytical methods detect the same $\mathrm{ZON}$ concentrations, identical to the nominal values, on the other hand. To assess possible matrix effects on immunosensor performance, the aqueous extracts were diluted 1:100 to 1:10,000 in $42 \mathrm{mM}$ 2-amino-2(hydroxymethyl)-1,3-propanediol (Tris) buffer ( $\mathrm{pH}$ 7.4). Figure 5 shows analytical standard curves obtained by the optimised competitive immunosensor setup in diluted maize extracts, and demonstrates that matrix effects are diluted out at 1:10,000. ZON concentrations detected by the competitive immunosensor indicated analytical recoveries at initial ZON concentrations between $5 \mathrm{ng} / \mathrm{kg}$ and $10 \mu \mathrm{g} / \mathrm{kg}$, carried out in triplicates, were found to be $84 \%$ and $124 \%$, mostly suitable for practical use. It has to be noted, however, that the maximal recovery value fell by $3.3 \%$ out of the acceptable recovery range of the European legislation performance criteria for ZON detection set to be $60-120 \%$ and $70-120 \%$ for ZON concentration at or below $50 \mu \mathrm{g} / \mathrm{kg}$ and above $50 \mu \mathrm{g} / \mathrm{kg}$, respectively [79].

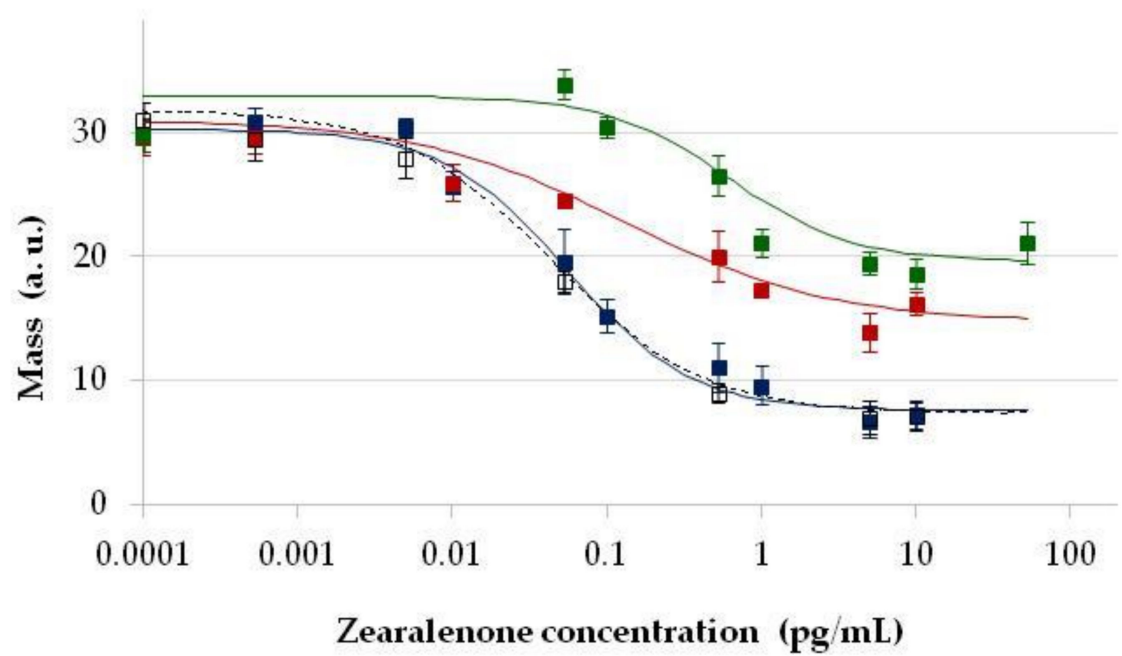

Figure 5. Standard calibration curves for zearalenone ( $\mathrm{ZON}$ ) determination by the competitive optical waveguide lightmode spectroscopy (OWLS) immunosensor format in maize extract at various dilutions. The amino-modified sensor surface with $\mathrm{ZON}$ conjugate to bovine serum albumin (ZONBSA) immobilised at $10 \mu \mathrm{g} / \mathrm{mL}$ on amino-modified sensor surfaces by (3-aminopropyl) triethoxysilane, succinic anhydride and 1-ethyl-3-(3-dimethylaminopropyl) carbodiimide with N-hydroxysuccinimide (APTS/SA/EDC-NHS) using ZON-specific serum at 1:2000 dilution. Maize extracts were applied at dilutions of 1:100 ( $\mathbf{\square}$, green line), 1:1000 ( $\boldsymbol{\square}$, red line), and 1:10,000 ( $\mathbf{\square}$, blue line); ZON calibration curve in 42 mM 2-amino-2-(hydroxymethyl)-1,3-propanediol (Tris) buffer (pH 7.4) ( $\square$, black slashed line).

ZON concentrations measured in maize extract by OWLS and ELISA methods were compared to each other as shown in Figure 6. Results indicate that concentrations detected by the two methods well correlated with each other in the $0.1-10 \mu \mathrm{g} / \mathrm{kg}$ range $\left(\mathrm{r}^{2}=0.984\right)$, and both methods are applicable. However, while the ELISA method required an extract dilution of 1:10 and detected ZON above $0.1 \mathrm{ng} / \mathrm{mL}$, the OWLS immunosensor required an extract dilution of 1:10,000, but detected $Z O N$ above $0.01 \mathrm{pg} / \mathrm{mL}$. 


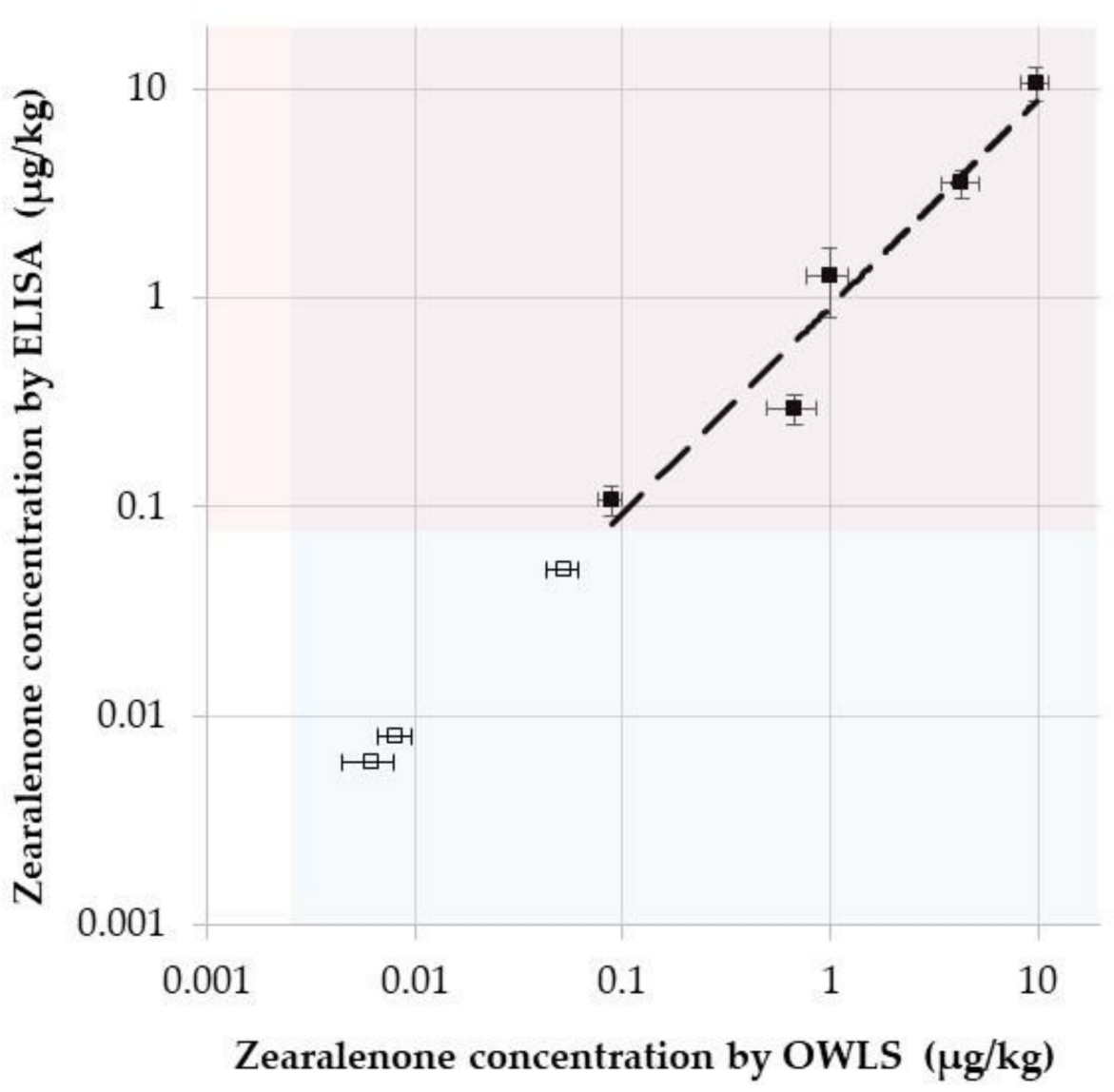

Figure 6. Determination of zearalenone ( $\mathrm{ZON})$ content in maize samples by optical waveguide lightmode spectroscopy (OWLS) immunosensor and enzyme-linked immunosorbent assay (ELISA). The sensing range for OWLS $(>0.002 \mu \mathrm{g} / \mathrm{kg})$ and for ELISA $(>0.09 \mu \mathrm{g} / \mathrm{kg})$ are indicated in blue and red, respectively. (Ordinate values for ZON concentrations below $0.09 \mu \mathrm{g} / \mathrm{kg}$ are virtual for visualisation-indicated by hollow rectangles).

\section{Conclusions}

To provide stable immunosensors for the detection of mycotoxin ZON, continuous flow OWLS sensor setups were established. To immobilize protein immunoreagents (ZONspecific antibodies or ZON-BSA conjugate), the immunosensor surface was modified by epoxy, amino, and carboxyl functional groups under laboratory conditions by optimised silanisation protocols. Epoxy functional groups allowed direct immobilisation of the proteins under alkaline conditions $(\mathrm{pH}=9.5)$. Amino functional groups allowed direct immobilisation of the proteins with $2.5 \% \mathrm{GA}$, or could be converted to carboxylic acid functional groups by $0.2 \% \mathrm{SA}$ and conjugate to proteins using a 1:1 mixture of $0.1 \mathrm{M}$ NHS and 0.4 M EDC.

In the direct (immobilised antibody) format, immobilisation on epoxy-modified surfaces (GOPS) provided lower binding efficacy and reproducibility than that on amino(APTS/GA) or carboxyl-modified surfaces (APTS/SA/EDC-NHS). However, detectable ZON concentrations fell in all three cases above $500 \mathrm{ng} / \mathrm{mL}$, not being sufficient for practical purposes. In the competitive (immobilised antigen) format, immobilisation on epoxy-modified surfaces (GOPS) remained improper for use, not providing sigmoid analyte concentration dependence, but amino- or carboxyl-modified surfaces were found of high utility. Both methods (APTS/GA and APTS/SA/EDC-NHS) resulted in similar analytical detection levels $\left(\mathrm{EC}_{50}\right.$ values in the range of $\left.0.017-0.083 \mathrm{pg} / \mathrm{mL}\right)$ and linear detection ranges. Higher signal levels—-therefore, greater signal decreases by inhibition - were achieved with amino-modified surfaces; however, carboxyl-modified surfaces allowed for 
more stable and reproducible results. The optimised competitive immunosensor using $10 \mu \mathrm{g} / \mathrm{mL}$ of ZON-BSA as the surface coating antigen immobilised by the APTS/SA/EDCNHS method, as well as ZON-specific antibodies at 1:2000 dilution, was found to show excellent sensitivity and specificity to ZON, allowed an LOD of $0.002 \mathrm{pg} / \mathrm{mL}$, and was found to be applicable to the determination of ZON in maize extracts. Detectable analyte concentrations in assay buffer were found to be five orders of magnitude lower by the immunosensor than by the related ELISA method, which, considering the sample preparation requirements, corresponds to a three orders of magnitude improvement for determination of ZON content in maize commodity. Such unique improvements in the analytical sensitivity of the OWLS technique compared to the corresponding ELISA method have previously been evidenced for the detection of other analytes, including a nearly three orders of magnitude enhancement for the endocrine biomarker protein vitellogenin [77] and a six orders of magnitude improvement for a herbicide active ingredient trifluralin [76] Moreover, the current OWLS immunosensor represents substantial advancements compared to previous immunosensors for ZON, e.g., based on SPR [71], TIRE [73], and electrochemical detection with antibodies immobilised on gold nanoparticles embedded on multi-walled carbon nanotubes [42], to which the LOD of the current competitive OWLS immunosensor represents 30,000-, 5000-, and 75-fold improvements, respectively.

\section{Materials and Methods}

\subsection{Reagents and Instrumentation}

Chemical reagents, including $\gamma$-glycidoxypropyl-trimethoxysilane (GOPS) and (3aminopropyl) triethoxysilane (APTS), mycotoxin standards, proteins, and biochemicals, were purchased from Sigma-Aldrich Kft. (Budapest, Hungary) unless indicated otherwise. OWLS immunosensor measurements were carried out on an OWLS 210 instrument and BioSense 3.8 software (MicroVacuum Ltd., Budapest, Hungary) using OWLS 2400 sensor chips with optical grating of 2400 lines per $\mathrm{mm}$ in the $\mathrm{SiO}_{2}-\mathrm{TiO}_{2}$ waveguide layer (MicroVacuum Ltd., Budapest, Hungary). Immunoassays were carried out in an iEMS MF microplate reader (LabSystems, Helsinki, Finland) using high-capacity 96-well microplates (Nunc, Roskilde, Denmark).

\subsection{Immunogen and Antibody Production}

Since $\mathrm{ZON}$ is low-molecular-weight hapten, it is non-immunogenic and should be conjugated to a protein carrier for immunisation. $\mathrm{ZON}$ was converted to the corresponding hapten, ZON-6'-carboxymethyloxime, and was conjugated to carrier proteins BSA and CONA by the method from the literature [26]. Polyclonal antibodies directed against ZON were produced in female, 3-month-old New Zealand white rabbits immunised periodically and intradermally with a standard mixture of $25 \mu \mathrm{g}$ of the ZON-CONA conjugate immunogen per kg body weight and $50 \mu \mathrm{L}$ of Freund's complete or incomplete adjuvant. Rabbit immunisation was carried out under the supervision of the Ethics Committee of Research on Animals (Food Science Research Institute, National Agricultural Research and Innovation Centre, Budapest, Hungary) and under the authorisation and inspection by the Government Office for Pest County in Hungary (Official permit for animal testing \# PE/EA/45-6/2020, last date of approval: 21 February 2020). Serum from the whole blood obtained was centrifuged at $2400 \mathrm{~g}$ for $15 \mathrm{~min}$, and its IgG fraction was purified by sodium-sulphate precipitation [80].

\subsection{OWLS Immunosensor Measurements}

OWLS sensoric determinations were carried out in a flow-through cell of the OWLS 210 instrument. The optical grating of the sensor surface is illuminated with a polarised He-Ne laser light $(632.8 \mathrm{~nm})$, and the sensor chip is rotated along its axis in a narrow angle range $\left( \pm 7^{\circ}\right)$. The laser beam is diffracted on the grating, and enters the waveguide at the characteristic incoupling angles, where it propagates by total internal reflection, and is detected by photodiodes at the ends of the waveguide layer. Incoupling of the incident laser 
beam occurs at two well-defined angles of incidence: one for transverse electric (TE) and one for transverse magnetic (TM) mode. Rotating the cuvette with \pm 7 degrees, effective refractive indices (NTE and NTM) are monitored, and four characteristic photocurrent peaks (TE and TM peaks on both, positive and negative sides) can be detected at the incoupling angles $\alpha \mathrm{TE}$ and $\alpha \mathrm{TM}$. Apparent incoupling angles can be measured with $10^{-4}$ degree accuracy, and signal resolution relative to the effective refraction index is $\Delta \mathrm{N} \sim 10^{-6}$. The mass of the deposited material absorbed on the waveguide surface from the continuous-flow medium can be calculated from the effective refractive indices (NTE and NTM), expressed as thickness of the protein layer deposited $(\mathrm{nm})$ or surface coverage $\left(\mathrm{ng} \mathrm{cm}^{-2}\right)$. All determinations were carried out at room temperature in a flow-injection analyser system at a flow rate of $200 \mu \mathrm{l} / \mathrm{min}$ and with injection volumes of $200 \mu \mathrm{L}$.

\subsubsection{Functionalisation of the Sensor Surface}

The sensor surface was derivatised by several routes to form reactive functional groups for covalent immobilisation of the protein immunoreagents (ZON-specific antibodies or ZON-BSA conjugate) (Figure 1). Proteins were immobilised to the derivatised sensor chip in a flow-through system using a $42 \mathrm{mM}$ Tris running buffer ( $\mathrm{pH}$ 7.4). Reactive epoxy groups were formed on the sensor surface by heating the sensor chips to $60^{\circ} \mathrm{C}$ in $10 \%$ GOPS in toluene for $20 \mathrm{hrs}$, followed by washing the chips with toluene and further heating to $100{ }^{\circ} \mathrm{C}$ for $1 \mathrm{hr}$. Epoxy functionalised surfaces allowed for direct anchoring of biomolecules carrying amino or hydroxy moieties by nucleophilic addition to them in alkaline medium $(\mathrm{pH}>8.5)$ [81]. Thus, protein immunoreagents were injected onto the epoxylated sensor chips at $1-20 \mu \mathrm{g} / \mathrm{mL}$ concentrations in $0.2 \mathrm{M}$ carbonate buffer at $\mathrm{pH} 9.5$, followed by buffer exchange to $42 \mathrm{mM}$ Tris buffer at $\mathrm{pH} 7.4$, and removal of unbound proteins from the surface by injecting $0.1 \mathrm{M}$ aqueous hydrochloric acid. Amino groups were formed on the surface of the sensor by treating the chips at $75^{\circ} \mathrm{C}$ with $10 \%$ APTS at pH 3.0 for $4 \mathrm{hrs}$, followed by washing with distilled water and heat treatment at $95{ }^{\circ} \mathrm{C}$ for $6 \mathrm{hrs}$ [81]. The amino functionality was activated with $2.5 \%$ aqueous glutaraldehyde (GA), allowing direct additive anchoring biomolecules carrying amino groups. The immobilisation reaction was carried out within the flow-through cuvette, by injecting GA into the flowing distilled water medium, followed by medium exchange to Tris buffer ( $42 \mathrm{mM}, \mathrm{pH} 7.4)$, subsequent injection of the proteins at $1-20 \mu \mathrm{g} / \mathrm{mL}$ concentration, and elution of the unbound reagent fraction by the injection of $0.1 \mathrm{M}$ aqueous hydrochloric acid. Alternatively, amino groups were modified to carboxyl groups by derivatisation with succinic anhydride (SA), and were utilised for covalent attachment of biomolecules by the activated ester method using NHS with a dehydrating agent EDC. Carboxylation was carried out in separate vessels with $1 \%$ SA in dry ethanol at $25^{\circ} \mathrm{C}$ for $1 \mathrm{hr}$, followed by drying the chips at $90^{\circ} \mathrm{C}$ for $15 \mathrm{~min}$. Active ester formation on the chip surface was carried out in a stopped flow mode by injecting a 1:1 solution of $0.2 \mathrm{M} \mathrm{EDC}$ and $0.05 \mathrm{M}$ NHS, incubating at room temperature for $10 \mathrm{~min}$, rinsing with Tris buffer $(42 \mathrm{mM}, \mathrm{pH} 7.4)$, adding the protein-ZON conjugate at $1-20 \mu \mathrm{g} / \mathrm{mL}$ concentration in $10 \mathrm{mM}$ sodium acetate buffer at $\mathrm{pH} 4.0$, and incubating again at room temperature for $10 \mathrm{~min}$. Alternatively, active ester formation could be carried out outside the OWLS 210 instrument, on a Petri dish, under similar reaction conditions. Residual active ester functional groups were finally deactivated by the injection of $1 \mathrm{M}$ ethanolamine at $\mathrm{pH} 8.5$ for $10 \mathrm{~min}$.

\subsubsection{Immunosensor Formats}

Non-competitive and competitive detection formats were applied for developing OWLS immunosensors. The first format was based on the immobilisation of 2000-fold diluted polyclonal antibodies. Such immobilised antibodies capture their analyte (the antigen or similar immunoreactive compounds) from the sample; therefore, this format is often also termed a direct format, and the amount of antigen bound to the immobilised antibodies is proportional to the quantity of the antigen in the standard solutions. In the second format, $10 \mu \mathrm{g} / \mathrm{mL}$ of ZON-BSA conjugate was bound to the solid surface, then standards or 
samples were mixed in a 1:1 ratio with solutions containing known amounts of antibodies, and the mixture upon a short incubation was injected into the system. The amount of antibodies bound to the immobilised conjugates is inversely proportional to the quantity of the antigen in the standard solutions.

\subsection{Sample Preparation}

Ground maize samples were spiked with $\mathrm{ZON}$ at the concentration range of $5 \mathrm{ng} / \mathrm{kg}$ to $10 \mu \mathrm{g} / \mathrm{kg}(5,10,50,100$, and $500 \mathrm{ng} / \mathrm{kg}$ and 1,5 , and $10 \mu \mathrm{g} / \mathrm{kg})$. One gram aliquots of the spiked samples were extracted with $10 \mathrm{~mL}$ of acetonitrile/water (6:4) as a solvent. The samples were stirred for $10 \mathrm{~min}$ and centrifuged on ultrafiltration membranes with a 100,000 nominal molecular weight limit at $5000 \mathrm{rpm}$ for $10 \mathrm{~min}$, and the filtrate was collected for OWLS and ELISA measurements. Upon sample preparation, all samples were stored at $4{ }^{\circ} \mathrm{C}$ until measurement and were diluted with $42 \mathrm{mM}$ Tris buffer (pH 7.4) to the appropriate rate prior to analysis.

\subsection{Determination of ZON by ELISA Method}

To confirm the utility of the immunosensor, ZON content was also determined in a corresponding competitive ELISA system [29]. ELISA plates were coated with $5 \mu \mathrm{g} / \mathrm{mL}$ ZON-BSA conjugate, and inhibition of binding of the polyclonal antibody by ZON was measured using a commercial horseradish peroxidase labelled second (anti-rabbit IgG) antibody and a colorimetric immunoassay signal measured at $450 \mathrm{~nm}$.

\subsection{Data Analysis and Statistics}

All determinations, except for the real time recordings in direct sensor titration experiments (Figure 3), were performed at least in triplicates, and error bars on the graphs represent the standard deviation (SD) of the replicates for each datum point. SDs were calculated as the square root of variance of the deviation of each datum point relative to the mean. Sigmoid calibration curves were obtained by logistic mathematical fitting using the Rodbard equation [82], which were also used for determination of the $\mathrm{IC}_{50}$ values. LOD values were defined as an analyte concentration corresponding to a signal that differs from the background level by 3 SDs of the background.

Author Contributions: Conceptualisation, I.S. (Inna Székács), N.A. and A.S.; methodology, I.S. (Inna Székács) and N.A.; software, I.S. (István Szendő); validation, I.S. (Inna Székács) and N.A.; formal analysis, N.A. and A.S.; investigation, I.S. (Inna Székács); resources, I.S. (István Szendő); data curation, I.S. (Inna Székács); writing—original draft preparation, I.S. (Inna Székács); writingreview and editing, N.A., I.S. (István Szendő) and A.S.; visualisation, A.S.; supervision, A.S.; project administration, A.S.; funding acquisition, N.A. and A.S. All authors have read and agreed to the published version of the manuscript.

Funding: This research was funded by the Hungarian National Research, Development and Innovation Office, project NVKP_16-1-2016-0049 “In situ, complex water quality monitoring by using direct or immunofluorimetry and plasma spectroscopy".

Institutional Review Board Statement: The study was conducted according to the guidelines of the Declaration of Helsinki, and approved by the Ethics Committee of Research on Animals of the Food Science Research Institute, National Agricultural Research and Innovation Centre, Budapest, Hungary (protocol code PE/EA/45-6/2020, last date of approval 21 February 2020).

Informed Consent Statement: Not applicable.

Data Availability Statement: The data presented in this study are available on request from the corresponding author. The data are not publicly available due to privacy reasons.

Conflicts of Interest: The authors declare no conflict of interest. 


\section{References}

1. Maragos, C.M. Zearalenone occurrence and human exposure. World Mycotoxin J. 2010, 3, 369-383. [CrossRef]

2. Kiang, D.T.; Kennedy, B.J.S.; Pathre, V.; Mirocha, C.J. Binding characteristicsof zearalenone analogs to estrogen receptors. Cancer Res. 1978, 38, 3611-3615.

3. Kuiper, G.G.J.M.; Lemmen, J.G.; Carlsson, B.; Corton, J.C.; Safe, S.H.; Van der Saag, P.T.; Van der Burg, B.; Gustafsson, J.A. Interaction of estrogenic chemicals and phytoestrogens with estrogen receptor beta. Endocrinology 1998, 139, 4252-4263. [CrossRef]

4. Zinedine, A.; Soriano, J.M.; Moltó, J.C.; Mañes, J. Review on the toxicity, occurrence, metabolism, detoxification, regulations and intake of zearalenone: An oestrogenic mycotoxin. Food Chem. Toxicol. 2007, 45, 1-18. [CrossRef]

5. Turcotte, J.C.; Hunt, P.J.B.; Blaustein, J.D. Estrogenic effects of zearalenone on the expression of progestin receptors and sexual behavior in female rats. Horm. Behav. 2005, 47, 178-184. [CrossRef]

6. Hueza, I.M.; Raspantini, P.C.F.; Raspantini, L.E.R.; Latorre, A.O.; Górniak, S.L. Zearalenone, an estrogenic mycotoxin, is an immunotoxic compound. Toxins 2014, 6, 1080-1095. [CrossRef]

7. Marin, D.E.; Motiu, M.; Taranu, I. Food contaminant zearalenone and its metabolites affect cytokine synthesis and intestinal epithelial integrity of porcine cells. Toxins 2015, 7, 1979-1988. [CrossRef]

8. Zhou, H.; George, S.; Hay, C.; Lee, J.; Qian, H.; Sun, X. Individual and combined effects of aflatoxin B1, deoxynivalenol and zearalenone on HepG2 and RAW 264.7 cell lines. Food Chem. Toxicol. 2017, 103, 18-27. [CrossRef]

9. Food and Agricultural Organization (FAO). Worldwide Regulations for Mycotoxins in Food and Feed in 2003; Food and Agricultural Organization of the United Nations: Rome, Italy, 2004.

10. European Commission (EC). Commission Regulation (EC) No 1881/2006 of 19 December 2006 setting maximum levels for certain contaminants in foodstuffs. Off. J. Eur. Union 2006, L 364, 5-24.

11. European Food Safety Authority (EFSA). Scientific Opinion on the risks for public health related to the presence of zearalenone in food. EFSA J. 2011, 9, 2197. [CrossRef]

12. European Food Safety Authority (EFSA). Scientific Opinion on the risks for animal health related to the presence of zearalenone and its modified forms in feed. EFSA J. 2017, 15, 4851.

13. Schaafsma, A.W.; Nicol, R.W.; Savard, M.E.; Sinha, R.C.; Reid, L.M.; Rottinghaus, G. Analysis of Fusarium toxins in maize and wheat using thin layer chromatography. Mycopathologia 1998, 142, 107-113. [CrossRef]

14. Josephs, R.D.; Shumacher, R.; Krska, R. International interlaboratory study for the determination of the Fusarium mycotoxins zearalenone and deoxynivalenol in agricultural commodities. Food Addit. Contam. 2001, 18, 417-430. [CrossRef]

15. Dawlatana, M.; Coker, R.D.; Nagler, M.J.; Blunden, G.; Oliver, W.O. An HPTLC method for the quantitative determination of zearalenone in maize. Chromatographia 1998, 47, 215-218. [CrossRef]

16. Diebold, G.J.; Karny, N.; Zare, R.N. Determination of zearalenone in corn by laser fluorimetry. Anal. Chem. 1979, 51, 67-69. [CrossRef] [PubMed]

17. Tanaka, T.; Teshima, R.; Ikebuchi, H.; Sawada, J.; Ichinoe, M. Sensitive enzyme-linked immunosorbent assay for the mycotoxin zearalenone in barley and Job's-tears. J. Agric. Food Chem. 1995, 43, 946-950. [CrossRef]

18. Kinani, S.; Bouchonnet, S.; Bourcier, S.; Porcher, J.M.; Aït-Aïssa, S. Study of the chemical derivatization of zearalenone and its metabolites for gas chromatography-mass spectrometry analysis of environmental samples. J. Chromatogr. A 2008, 1190, 307-315. [CrossRef]

19. Radová, Z.; Hajšlová, J.; Králová, J. Analysis of zearalenone in wheat using high-performance liquid chromatography with fluorescence detection and/or enzyme-linked immunosorbent assay. Cereal Res. Commun. 2001, 29, 435-442. [CrossRef]

20. Berthiller, F.; Schumacher, R.; Buttinger, G.; Krska, R. Rapid simultaneous determination of major type A- and B-trichothecenes as well as zearalenone in maize by high performance liquid chromatography-tandem mass spectrometry. J. Chromatogr. A 2005, 1062, 209-216. [CrossRef]

21. Ok, H.E.; Chung, S.H.; Lee, N.; Chun, H.S. Simple high-performance liquid chromatography method for the simultaneous analysis of aflatoxins, ochratoxin A, and zearalenone in dried and ground red pepper. J. Food Prot. 2015, 78, 1226-1231. [CrossRef]

22. Nakhjavan, B.; Ahmed, N.S.; Khosravifard, M. Development of an improved method of sample extraction and quantitation of multi-mycotoxin in feed by LC-MS/MS. Toxins 2020, 12, 462. [CrossRef] [PubMed]

23. Rausch, A.-K.; Brockmeyer, R.; Schwerdtle, T. Development and validation of a QuEChERS-based liquid chromatography tandem mass spectrometry multi-method for the determination of 38 native and modified mycotoxins in cereals. J. Agric. Food Chem. 2020, 68, 4657-4669. [CrossRef] [PubMed]

24. Sun, S.; Yao, K.; Zhao, S.; Zheng, P.; Wang, S.; Zeng, Y.; Liang, D.; Ke, Y.; Jiang, H. Determination of aflatoxin and zearalenone analogs in edible and medicinal herbs using a group-specific immunoaffinity column coupled to ultra-high-performance liquid chromatography with tandem mass spectrometry. J. Chromatogr. B 2018, 1092, 228-236. [CrossRef] [PubMed]

25. Holland, R.D.; Sepaniak, M.J. Qualitative analysis of mycotoxins using micellar electrokinetic capillary chromatography. Anal. Chem. 1993, 65, 1140-1146. [CrossRef]

26. Böhs, B.; Seidel, V.; Lindner, W. Analysis of selected mycotoxins by capillary electrophoresis. Chromatographia 1995, 41, 631-637. [CrossRef]

27. Thouvenot, D.; Morfin, R.F. Radioimmunoassay for zearalenone and zearalanol in human serum: Production, properties, and use of porcine antibodies. Appl. Environ. Microbiol. 1983, 45, 16-23. [CrossRef] 
28. Liu, M.T.; Ram, B.P.; Hart, L.P.; Pestka, J.J. Indirect enzyme-linked immunosorbent assay for the mycotoxin zearalenone. Appl. Environ. Microbiol. 1985, 50, 332-336. [CrossRef]

29. Székács, A. Enzyme-linked immunosorbent assay for monitoring the Fusarium toxin zearalenone. Food Technol. Biotechnol. 1998, $36,105-110$.

30. Pichler, H.; Krska, R.; Székács, A.; Grasserbauer, M. An enzyme-immunoassay for the detection of the mycotoxin zearalenone by use of yolk antibodies. Fresenius J. Anal. Chem. 1998, 362, 176-177. [CrossRef]

31. Thongrussamee, T.; Kuzmina, N.S.; Shim, W.-B.; Jiratpong, T.; Eremin, S.A.; Intrasook, J.; Chung, D.-H. Monoclonal-based enzyme-linked immunosorbent assay for the detection of zearalenone in cereals. Food Addit. Contam. A 2008, 25, 997-1006. [CrossRef]

32. Tang, X.; Li, X.; Li, P.; Zhang, Q.; Li, R.; Zhang, W.; Ding, X.; Lei, J.; Zhang, Z. Development and application of an immunoaffinity column enzyme immunoassay for mycotoxin zearalenone in complicated samples. PLoS ONE 2014, 9, e85606. [CrossRef]

33. Dong, G.; Pan, Y.; Wang, Y.; Ahmed, S.; Liu, Z.; Peng, D.; Yuan, Z. Preparation of a broad-spectrum anti-zearalenone and its primary analogues antibody and its application in an indirect competitive enzyme-linked immunosorbent assay. Food Chem. 2018, 247, 8-15. [CrossRef]

34. Zhan, S.; Huang, X.; Chen, R.; Li, J.; Xiong, Y. Novel fluorescent ELISA for the sensitive detection of zearalenone based on $\mathrm{H} 2 \mathrm{O} 2-$ sensitive quantum dots for signal transduction. Talanta 2016, 158, 51-56. [CrossRef]

35. Beloglazova, N.V.; Speranskaya, N.V.; Wu, A.; Wang, Z.; Sanders, M.; Goftman, V.V.; Zhang, D.; Goryacheva, I.Y.; De Saeger, S. Novel multiplex fluorescent immunoassays based on quantum dot nanolabels for mycotoxins determination. Biosens. Bioelectron. 2014, 62, 59-65. [CrossRef] [PubMed]

36. Zhang, F.; Liu, B.; Sheng, W.; Zhang, Y.; Liu, Q.; Li, S.; Wang, S. Fluoroimmunoassays for the detection of zearalenone in maize using CdTe/CdS/ZnS quantum dots. Food Chem. 2018, 255, 421-428. [CrossRef] [PubMed]

37. Hendrickson, O.D.; Chertovich, J.O.; Zherdev, A.V.; Sveshnikov, P.G.; Dzantiev, B.B. Ultrasensitive magnetic ELISA of zearalenone with pre-concentration and chemiluminescent detection. Food Control 2018, 84, 330-338. [CrossRef]

38. Fang, D.; Zeng, B.; Zhang, S.; Dai, H.; Lin, Y. A self-enhanced electrochemiluminescent ratiometric zearalenone immunoassay based on the use of helical carbon nanotubes. Microchim. Acta 2020, 187, 303. [CrossRef]

39. Visconti, A.; Pascale, M. Determination of zearalenone in corn by means of immunoaffinity clean-up and high-performance liquid chromatography with fluorescence detection. J. Chromatogr. A 1998, 815, 133-140. [CrossRef]

40. Fazekas, B.; Tar, A. Determination of zearalenone content in cereals and feedstuffs by immunoaffinity column coupled with liquid chromatography. J. AOAC Int. 2001, 84, 1453-1459. [CrossRef]

41. Hao, K.; Suryoprabowo, S.; Song, S.; Liu, L.; Kuang, H. Rapid detection of zearalenone and its metabolite in corn flour with the immunochromatographic test strip. Food Agric. Immunol. 2018, 29, 498-510. [CrossRef]

42. Riberi, W.I.; Tarditto, L.V.; Zon, M.A.; Arévalo, F.J.; Fernández, H. Development of an electrochemical immunosensor to determine zearalenone in maize using carbon screen printed electrodes modified with multi-walled carbon nanotubes/polyethyleneimine dispersions. Sens. Actuators B 2018, 254, 1271-1277. [CrossRef]

43. Xu, L.; Zhang, Z.; Zhang, Q.; Zhang, W.; Yu, L.; Wang, D.; Li, H.; Li, P. An on-site simultaneous semi-quantification of aflatoxin b1, zearalenone, and T-2 toxin in maize- and cereal-based feed via multicolor immunochromatographic assay. Toxins 2018, 10, 87. [CrossRef] [PubMed]

44. Li, S.-J.; Sheng, W.; Wen, W.; Gu, Y.; Wang, J.-P.; Wang, S. Three kinds of lateral flow immunochromatographic assays based on the use of nanoparticle labels for fluorometric determination of zearalenone. Microchim. Acta 2018, 185, 238. [CrossRef] [PubMed]

45. Gadzała-Kopciuch, R.; Cendrowski, K.; Cesarz, A.; Kiełbasa, P.; Buszewski, B. Determination of zearalenone and its metabolites in endometrial cancer by coupled separation techniques. Anal. Bioanal. Chem. 2011, 401, 2069-2078. [CrossRef]

46. Lhotská, I.; Gajdošová, B.; Solich, P.; Šatínský, D. Molecularly imprinted vs. reversed-phase extraction for the determination of zearalenone: A method development and critical comparison of sample clean-up efficiency achieved in an on-line coupled SPE chromatography system. Anal. Bioanal. Chem. 2018, 410, 3265-3273.

47. Zhang, Y.; He, J.; Song, L.; Wang, H.; Huang, Z.; Sun, Q.; Ba, X.; Li, Y.; You, L.; Zhang, S. Application of surface-imprinted polymers supported by hydroxyapatite in the extraction of zearalenone in various cereals. Anal. Bioanal. Chem. 2020, 412, 4045-4055. [CrossRef]

48. Huang, X.; Aguilar, Z.P.; Xu, H.; Lai, W.; Xiong, Y. Membrane-based lateral flow immunochromatographic strip with nanoparticles as reporters for detection: A review. Biosens. Bioelectron. 2016, 75, 166-180. [CrossRef]

49. Wu, Y.; Zhou, Y.; Huang, H.; Chen, X.; Leng, Y.; Lai, W.; Huang, X.; Xiong, Y. Engineered gold nanoparticles as multicolor labels for simultaneous multi-mycotoxin detection on the immunochromatographic test strip nanosensor. Sens. Actuators B 2020, 316, 128107. [CrossRef]

50. Zhang, W.; Tang, S.; Jina, Y.; Yang, C.; He, L.; Wang, J.; Chen, Y. Multiplex SERS-based lateral flow immunosensor for the detection of major mycotoxins in maize utilizing dual Raman labels and triple test lines. J. Hazard. Mater. 2020, 393, 122348. [CrossRef]

51. McNamee, S.E.; Bravin, F.; Rosar, G.; Elliott, C.T.; Campbell, K. Development of a nanoarray capable of the rapid and simultaneous detection of zearalenone, T2-toxin and fumonisin. Talanta 2017, 164, 368-376. [CrossRef]

52. Chen, Y.; Meng, X.; Zhu, Y.; Shen, M.; Lu, Y.; Cheng, J.; Xu, Y. Rapid detection of four mycotoxins in corn using a microfluidics and microarray-based immunoassay system. Talanta 2018, 186, 299-305. [CrossRef] 
53. Basova, E.Y.; Goryacheva, I.Y.; Rusanova, T.Y.; Burmistrova, N.A.; Dietrich, R.; Märtlbauer, E.; Detavernier, C.; Van Peteghem, C.; De Saeger, S. An immunochemical test for rapid screening of zearalenone and T-2 toxin. Anal. Bioanal. Chem. 2010, 397, 55-62. [CrossRef]

54. Chun, H.S.; Choi, E.H.; Chang, H.J.; Choi, S.W.; Eremin, S.A. A fluorescence polarization immunoassay for the detection of zearalenone in corn. Anal. Chim. Acta 2009, 639, 83-89. [CrossRef]

55. Mak, A.C.; Osterfeld, S.J.; Yu, H.; Wang, S.X.; Davis, R.W.; Jejelowo, O.A.; Pourmand, N. Sensitive giant magnetoresistive-based immunoassay for multiplex mycotoxin detection. Biosens. Bioelectron. 2010, 25, 1635-1639. [CrossRef]

56. Shao, Y.; Duan, H.; Guo, L.; Leng, Y.; Lai, W.; Xiong, Y. Quantum dot nanobead-based multiplexed immunochromatographic assay for simultaneous detection of aflatoxin $\mathrm{B}_{1}$ and zearalenone. Anal. Chim. Acta 2018, 1025, 163-171. [CrossRef]

57. Urraca, J.L.; Benito-Peña, E.; Pérez-Conde, C.; Moreno-Bondi, M.C.; Pestka, J.J. Analysis of zearalenone in cereal and swine feed samples using an automated flow-through immunosensor. J. Agric. Food Chem. 2005, 53, 3338-3344. [CrossRef]

58. Xu, L.; Zhang, Z.; Zhang, Q.; Li, P. Mycotoxin determination in foods using advanced sensors based on antibodies or aptamers. Toxins 2016, 8, 239. [CrossRef]

59. Adányi, N.; Majer-Baranyi, K.; Székács, A. Evanescent field effect based nanobiosensors for agro-environmental and food safety. In Nanobiosensors: Nanotechnology in the Agri-Food Industry; Grumezescu, A.M., Ed.; Elsevier: Amsterdam, The Netherlands, 2017; Volume 8, pp. 429-474.

60. Goud, Y.K.; Kumar, S.V.; Hayat, K.; Gobi, V.K.; Song, H.; Kim, K.-H.; Marty, J.L. A highly sensitive electrochemical immunosensor for zearalenone using screen-printed disposable electrodes. J. Electroanal. Chem. 2019, 832, 336-342. [CrossRef]

61. Rhouati, A.; Catanante, G.; Nunes, G.; Hayat, A.; Marty, J.-L. Label-free aptasensors for the detection of mycotoxins. Sensors 2016, 16, 2178. [CrossRef]

62. Wu, S.; Liu, L.; Duan, N.; Li, Q.; Zhou, Y.; Wang, Z. Aptamer-Based Lateral Flow Test strip for rapid detection of zearalenone in corn samples. J. Agric. Food Chem. 2018, 66, 1949-1954. [CrossRef] [PubMed]

63. Taghdisi, S.M.; Danesh, N.M.; Ramezani, M.; Emrani, A.S.; Abnous, K. Novel colorimetric aptasensor for zearalenone detection based on nontarget-induced aptamer walker, gold nanoparticles, and exonuclease-assisted recycling amplification. ACS Appl. Mater. Interfaces 2018, 10, 12504-12509. [CrossRef] [PubMed]

64. He, D.; Wu, Z.; Cui, B.; Jin, Z.; Xu, E. A fluorometric method for aptamer-based simultaneous determination of two kinds of the fusarium mycotoxins zearalenone and fumonisin B-1 making use of gold nanorods and upconversion nanoparticles. Microchim. Acta 2020, 187, 254. [CrossRef] [PubMed]

65. Xu, J.; Chi, J.; Lin, C.; Lin, X.; Xie, Z. Towards high-efficient online specific discrimination of zearalenone by using gold nanoparticles@aptamer-based affinity monolithic column. J. Chromatogr. A 2020, 1620, 461026. [CrossRef] [PubMed]

66. Tan, H.; Guo, T.; Zhou, H.; Dai, H.; Yu, Y.; Zhu, H.; Wang, H.; Fu, Y.; Zhang, Y.; Ma, L. A simple mesoporous silica nanoparticlebased fluorescence aptasensor for the detection of zearalenone in grain and cereal products. Anal. Bioanal. Chem. 2020, 412, 5627-5635. [CrossRef] [PubMed]

67. Luo, L.; Liu, X.; Ma, S.; Li, L.; You, T. Quantification of zearalenone in mildewing cereal crops using an innovative photoelectrochemical aptamer sensing strategy based on ZnO-NGQDs composites. Food Chem. 2020, 322, 126778. [CrossRef] [PubMed]

68. Navarro-Villoslada, F.; Urraca, J.L.; Moreno-Bondi, M.C.; Orellana, G. Zearalenone sensing with molecularly imprinted polymers and tailored fluorescent probes. Sensors Actuators B 2007, 121, 67-73. [CrossRef]

69. Choi, S.W.; Chang, H.J.; Lee, N.; Kim, J.H.; Chun, H.S. Detection of mycoestrogen zearalenone by a molecularly imprinted polypyrrole-based surface plasmon resonance (SPR) sensor. J. Agric. Food Chem. 2009, 57, 1113-1118. [CrossRef]

70. Radi, A.-E.; Eissa, A.; Wahdan, T. Molecularly imprinted impedimetric sensor for determination of mycotoxin zearalenone. Electroanalysis 2020, 32, 1788-1794. [CrossRef]

71. Hu, X.; Wang, C.; Zhang, M.; Zhao, F.; Zeng, B. Ionic liquid assisted molecular self-assemble and molecular imprinting on gold nanoparticles decorated boron-doped ordered mesoporous carbon for the detection of zearalenone. Talanta 2020, $217,121032$. [CrossRef]

72. Tittlemier, S.A.; Cramer, B.; Dall'Asta, C.; Iha, M.H.; Lattanzio, V.M.T.; Malone, R.J.; Maragos, C.; Solfrizzo, M.; StranskaZachariasova MStroka, J. Developments in mycotoxin analysis: An update for 2017-2018. World Mycotoxin J. 2019, 12, 3-29. [CrossRef]

73. Van der Gaag, B.; Spath, S.; Dietrich, H.; Stigter, E.; Boonzaaijer, G.; van Osenbruggen, T.; Koopal, K. Biosensors and multiple mycotoxin analysis. Food Control 2003, 14, 251-254. [CrossRef]

74. Hossain, M.Z.; Maragos, C.M. Gold nanoparticle-enhanced multiplexed imaging surface plasmon resonance (iSPR) detection of Fusarium mycotoxins in wheat. Biosens. Bioelectron. 2018, 101, 245-252. [CrossRef] [PubMed]

75. Nabok, A.; Tsargorodskaya, A.; Mustafa, M.K.; Székács, I.; Starodub, N.F.; Székács, A. Detection of low molecular weight toxins using an optical phase method of ellipsometry. Sens. Actuators B 2011, 154, 232-237. [CrossRef]

76. Adányi, N.; Levkovets, I.A.; Rodriguez-Gil, S.; Ronald, A.; Váradi, M.; Szendrő, I. Development of immunosensor based on OWLS technique for determining Aflatoxin B1 and Ochratoxin A. Biosens. Bioelectron. 2007, 22, 797-802. [CrossRef]

77. Majer-Baranyi, K.; Adányi, N.; Nagy, A.; Bukovkaya, O.; Szendrő, I.; Székács, A. Label-free immunosensor for monitoring vitellogenin as a biomarker for exogenous oestrogen compounds in amphibian species. Int. J. Environ. Anal. Chem. 2015, 95, 481-493. [CrossRef] 
78. Székács, A.; Trummer, N.; Adányi, N.; Váradi, M.; Szendrő, I. Development of a non-labeled immunosensor for the herbicide trifluralin via OWLS detection. Anal. Chim. Acta 2003, 487, 31-42. [CrossRef]

79. EC (European Commission). Commission regulation (EC) No 519/2014. Off. J. Eur. Union 2014, L 147, $29-43$.

80. Tijssen, P. Practice and Theory of Enzyme Immunoassays; Elsevier: Amsterdam, The Netherlands, 1985; pp. 96-99.

81. Trummer, N.; Adányi, N.; Váradi, M.; Szendrő, I. Modification of the surface of integrated optical waveguide sensors for immunosensor applications. Fresenius J. Anal. Chem. 2001, 371, 21-24. [CrossRef]

82. Rodbard, D.; Hutt, D.M. Statistical analysis of radioimmunoassays and immunoradiometric (labeled antibody) assays: A generalized, weighted, iterative, least-squares method for logistic curve fitting. In Radioimmunoassay and Related Procedures in Medicine; International Atomic Energy Agency: Vienna, Austria, 1974; p. 165. 